\title{
O Lugar de Christian Wolff na História da Psicologia*
}

\section{The Role of Christian Wolff in the History of Psychology}

Recibido: septiembre 19 de 2011 | Revisado: diciembre 1 de 2011 | Aceptado: enero 10 de 2012

\author{
SaUlo De Freitas ARAujo ** \\ Universidad Federal de Juiz de Fora, Minas Gerais, Brasil
}

\section{RES UMO}

Christian Wolff (1679-1754) foi uma figura fundamental não só na cultura alemã do século XVIII como também no desenvolvimento histórico da psicologia. No entanto, sua obra permanece desconhecida por grande parte dos psicólogos contemporâneos. O objetivo do presente artigo é mostrar a importância de Wolff na constituição histórica da psicologia. Inicialmente, será feita uma breve contextualização histórico-cultural do Iluminismo alemão. Em seguida, mostraremos a íntima relação entre seu projeto psicológico e seu sistema filosófico. Finalmente, serão destacados alguns exemplos da influência de Wolff sobre o desenvolvimento posterior da psicologia. Conclui-se que ele merece maior atenção do que tem até aqui recebido na historiografia da psicologia em geral.

Palavras-chave autor:

Christian Wolff, história da psicologia, historiografia da psicologia.

\section{A B S T R A C T}

Christian Wolff (1679-1754) was a central figure not only in the German culture from the eighteenth century, but also in the historical development of psychology. However, his work remains largely unknown by most contemporary psychologists. The aim of this paper is to show Wolff's important role in the historical formation of psychology. We begin by offering a brief context of German Enlightenment in its historical-cultural aspects. Afterwards the close relationship between his psychological thought and his philosophical system will be shown. Finally, a few cases that illustrate Wolff's influence on the posterior development of psychology will be presented. We conclude that he deserves much more attention than he has received so far in the historiography of psychology in general.

Key words author:

Christian Wolff, history of psychology, historiography of psychology. 
Embora tenha sido um dos personagens mais influentes em toda a história da cultura alemã, Christian Wolff (1679-1754) não tem recebido a devida atenção por parte dos psicólogos contemporâneos. Se considerarmos, por exemplo, alguns dos livros mais utilizados no ensino de história da psicologia ao longo das últimas décadas, torna-se flagrante a pouca importância a ele atribuída. Ou seu nome não chega a ser sequer mencionado (e.g., Goodwin, 2005; Robinson, 1995; Schultz \& Schultz, 2006) ou então aparece apenas de forma superficial, como um mero coadjuvante entre miríades de autores mais importantes (e.g., Boring, 1950; Hehlmann, 1967; Leahey, 1980; Mueller, 1978; Murphy, 1949; Viney \& Brett King, 2003; Wehner, 1990). Boring, um dos mais destacados e influentes historiadores da psicologia, chega mesmo a afirmar que a influência de Wolff sobre os psicólogos alemães foi pouco significativa (Boring, 1950, p. 246).

É curioso notar, por outro lado, que essa situação geral contrasta de maneira clara, por um lado, com antigos trabalhos sobre a história da psicologia alemã (e.g., Dessoir, 1901/1964; Klemm, 1911; Sommer, 1892/1966); por outro, com investigações detalhadas tanto sobre a psicologia no século XVIII quanto sobre as suas raízes filosóficas em geral (e.g., Carus, 1808/1990; Mei, 2011; Misiak, 1961; Pongratz, 1967; Richards, 1992; Sturm, 2009; Vidal, 2006). Em ambos os casos, abundam as referências sobre Wolffe sua importância capital no desenvolvimento histórico da psicologia. Além disso, tendo em vista a reedição crítica de suas obras (Gesammelte Werke) a partir da década de 1960, surgiram trabalhos dedicados inteiramente à exposição e discussão tanto de sua filosofia quanto de sua psicologia (e.g., Bissinger, 1970; École, 1985; Gerlach, 2001; Rudolph \& Goubet, 2004; Schneiders, 1983a). Infelizmente, porém, essa profusão de material bibliográfico parece não ter sido suficiente para produzir um impacto na concepção geral do papel de Wolff no desenvolvimento histórico da psicologia. No Brasil, a situação é ainda mais grave, na medida em que há uma carência absoluta de estudos sobre o tema em questão.

Partindo da situação acima descrita, o objetivo do presente artigo é destacar a importância do pensamento de Wolff na constituição daquilo que veio a se chamar de "psicologia científica". Inicialmente, faremos uma breve exposição sobre a relação entre Wolff e o contexto cultural alemão do século XVIII. Logo em seguida, será apresentada a sua concepção de filosofia, destacando aí o lugar que a psicologia nela ocupa. Só então estaremos em condições de esclarecer o sentido e a importância que esta adquire, levando em conta a distinção por ele proposta entre 'psicologia empírica' e 'psicologia racional'. Finalmente, ressaltaremos os aspectos que ligam o pensamento de Wolff ao desenvolvimento posterior da psicologia alemã, enfatizando a questão da continuidade histórica e intelectual na tradição psicológica.

\section{Wolff e o Iluminismo Alemão}

A melhor maneira de situar histórica e culturalmente o pensamento de Wolff é relacioná-lo ao período que ficou conhecido como o "iluminismo alemão" (Aufklärung), que abrange praticamente todo o século XVIII. Se sua importância histórica não foi desde sempre reconhecida na literatura secundária, como mostrou Frängsmyr (1975), a idéia de que ele ocupa um lugar central nesse período da história intelectual alemã tem sido compartilhada, por outro lado, por grande parte dos historiadores tanto da filosofia quanto da cultura em geral (e.g., Beck, 1969; Bossenbrook, 1961; Cassirer, 1932/1997; Copleston, 1960/1994; Gay, 1966/1995; Hazard, 1946/1989; Paulsen, 1895; Pütz, 1978; Schöffler, 1956; Schwaiger, 2000; Wolff, 1949; Wundt, 1945/1964).

Nascido em Breslau (hoje pertencente à Polônia) em janeiro de 1679 , Wolff teve sua educação inicial em torno das controvérsias teológicas típicas do período posterior à Reforma. Insatisfeito com as incertezas do conhecimento teológico, ele começou a se interessar pela certeza matemática, o que acabou levando-o a se matricular na Universidade de Jena, em 1699. Lá ele estudou filosofia natural e matemática, indo posteriormente para Leipzig, onde defendeu, em 1702, uma dissertação sobre a aplicação do método matemático aos problemas da filosofia prática (Philosophia practica universalis 
mathematica methodo conscripta), tornando-se, assim, um Privatdozent (grau mais baixo da carreira docente nas universidades alemãs) em matemática. Seu sucesso na matemática chamou a atenção do já famoso Leibniz (1646-1716), que o recomendou à Universidade de Halle, onde foi nomeado Professor em 1706. Em Halle, no entanto, seus cursos começaram a incomodar os teólogos pietistas daquela instituição, que o acusavam de defender o ateísmo e o determinismo. Em 1723, Frederico Guilherme I, rei da Prússia, decretou sua expulsão não só daquela universidade, mas do território prussiano como um todo, e posteriormente proibiu que seus livros fossem utilizados e ensinados nas instituições prussianas. Wolff foi para a Universidade de Marburg, onde lecionou pelos próximos 17 anos e publicou suas obras mais importantes. Em 1740, após assumir o trono deixado pelo pai, Frederico o Grande chama Wolff de volta a Halle. Já com fama e prestígio, ele foi aclamado e recebido como herói pelo povo. Passou o resto de seus dias em Halle, vindo a falecer em abril de 1754 (Beck, 1969).

Ao longo de sua prolífica e bem sucedida carreira profissional, Wolff deu contribuições seminais à cultura alemã. Em primeiro lugar, deve-se ressaltar o grande serviço que prestou à transmissão do conhecimento matemático. Embora alguns tratados sobre ramos individuais da matemática já tivessem sido publicados em alemão anteriormente, seus manuais foram os primeiros a abranger toda a matemática de seu tempo e estabeleceram um vocabulário matemático básico para a língua alemã, que foi prontamente adotado nas universidades e ainda hoje permanece praticamente intacto (Blackall, 1959; Tonelli, 1967).

Foi, porém, no campo da filosofia que as realizações de Wolff tiveram um impacto ainda maior. Assim como no caso da matemática, ele também estabeleceu a terminologia básica da filosofia alemã com seus tratados publicados entre 1713 e 1726 em alemão (Blackall, 1959). Por si só isso já seria suficiente para assegurar sua importância no iluminismo alemão. Mas ele ocupa também um lugar de destaque na principal discussão metodológica da filosofia alemã do século XVIII, a saber, o papel do método matemático na construção do conheci- mento filosófico (Ciafardone, 1983; Engfer, 1983; Frängsmyr, 1975; Tonelli, 1959) - um tema central na virada crítica de Kant (1781/1995).

Pouco após sua expulsão de Halle em 1723, Wolff iniciou a fase que lhe rendeu mais fama e prestígio: a publicação de seu sistema de filosofia em latim. Vários alunos, vindos de toda a parte da Europa, chegaram a Marburg para ouvir suas preleções. Foi entre 1728 e 1740 - antes de regressar a Halle, portanto - que ele publicou seus tratados filosóficos mais influentes (Lógica, Ontologia, Cosmologia, Teologia), incluindo aí seus dois clássicos volumes sobre a psicologia (Wolff, 1732/1964, 1734/1966).

Por sua grande influência na vida intelectual e cultural da Alemanha, Wolff recebeu o título de "educador da nação alemã" (praeceptor Germania) (Beck, 1969; Cassirer, 1932/1997; Copleston, 1960/1994; Wundt, 1945/1960). E muito embora esse título possa carregar consigo certo exagero, como bem advertiu Hammerstein (1983), os efeitos de seu sistema filosófico de forma alguma se restringem aos países de língua alemã. Nesse sentido, há que se considerar ainda a disseminação de seu pensamento em vários países da Europa (Frängsmyr, 1975; Röhling, 1983). Tudo isso nos leva a apoiar, em termos gerais, o veredicto de Hinske (1983), de acordo com o qual é impossível compreender adequadamente os temas centrais da filosofia do iluminismo alemão abrindo mão da figura de Wolff.

\section{O Projeto Filosófico de Wolff}

Após ter resolvido não mais publicar seus livros em alemão, a fim de alcançar um público mais amplo, Wolff inicia então a fase dos escritos latinos, que contém a exposição mais completa e detalhada de seu sistema filosófico, embora isso não implique nenhuma alteração substantiva em relação aos textos iniciais (González Ruiz, 2000). Assim, ele publica, em 1728, uma introdução geral a todas as suas investigações filosóficas subseqüentes, que contém a mais clara apresentação de sua teoria e de seu método científico - o "Discurso Preliminar Sobre a Filosofia em Geral” (Discursus praeliminaris de philosophia in genere). É esta obra que tomaremos 
aqui como guia para nossa exposição, uma vez que ela representa a sistematização definitiva do pensamento de Wolff.

Antes, porém, de adentrarmos seu projeto propriamente filosófico, convém esclarecer que, para Wolff, a filosofia é apenas uma das formas que o conhecimento humano pode assumir. Em primeiro lugar, é possível conhecer as coisas que existem e acontecem no mundo, como, por exemplo, o fato de que o sol nasce pela manhã e se põe ao entardecer. Trata-se de uma constatação a partir da experiência comum, que Wolff chama de história (Wolff, 1728/2006, p. 4). É importante não tomarmos aqui o termo 'história' na sua acepção contemporânea, relacionada ao estudo e à compreensão do passado. No sistema wolffiano, história é mero conhecimento factual. Há, contudo, um segundo nível epistêmico, que ultrapassa a constatação histórica. Admitindo, sob a influência de Leibniz, como princípio máximo do conhecimento humano o princípio de razão suficiente - segundo o qual tudo o que existe ou acontece tem uma razão para tanto -, Wolff afirma que o homem não se contenta com a mera ocorrência ou existência das coisas; ele também se pergunta pela razão das mesmas. Nesse exato momento, surge então uma busca pelo conhecimento filosófico, o único que pode explicar a existência ou ocorrência das coisas no mundo. Nesse sentido, não bastaria saber, por exemplo, que o arco-íris às vezes aparece, mas seria preciso descobrir que ele só pode aparecer se os raios do sol incidirem sobre as gotas d'água segundo uma lei específica. Temos então uma nítida diferença entre conhecer um fato, de um lado, e a sua razão (Grund), de outro. Somente neste último caso poderíamos falar de filosofia (Wolff, pp. 4-5). Por último, uma vez que todas as coisas que existem ou ocorrem possuem uma determinada quantidade - quer dizer, elas podem aumentar ou diminuir em algum aspecto (o calor de um corpo, por exemplo) -, surge a necessidade de um conhecimento que estabeleça esta quantidade. Essa tarefa cabe à matemática (Wolff, pp. 8-10).

É importante ressaltar aqui que essa divisão proposta por Wolff de modo algum significa que as partes envolvidas devam ser encaradas como compartimentos estáticos e isolados entre si. O próprio Wolff fez questão de esclarecer que há um encadeamento dinâmico entre elas. Em primeiro lugar, o conhecimento histórico fornece o fundamento para a filosofia, na medida em que é a experiência que estabelece as coisas para as quais será buscada uma razão. A história deve preceder e estar constantemente ligada à filosofia. O filósofo não pode, portanto, desprezar os fatos empíricos, mesmo nas suas disciplinas mais abstratas (como a ontologia, por exemplo). E até mesmo a matemática pressupõe esse conhecimento para alguns dos seus axiomas e para a construção de seu objeto (Wolff, 1728/2006, pp. 7-8). Essa preocupação de Wolff em assegurar desde o início um lugar para a experiência na construção de seu sistema revela uma assimilação dos ataques empiristas ao apriorismo dos filósofos racionalistas e uma busca de melhor integração entre os dados sensoriais e a análise racional (Arndt, 1983; Blackwell, 1961). Se existe, pois, uma relação dinâmica entre história, filosofia e matemática, há, contudo, uma nítida diferença de complexidade entre elas. Como o conhecimento histórico é adquirido diretamente pelos sentidos, ele não pressupõe nenhum conhecimento que lhe seja anterior e lhe sirva de premissa para a dedução de uma cadeia de provas. Por isso, ele deve ser considerado o nível mais baixo do conhecimento humano. Num plano mais elevado encontra-se a filosofia, que deve fornecer a razão do conhecimento histórico. Entretanto, para que ela possa atingir a máxima certeza e alcançar o grau mais elevado possível de conhecimento, ela deve se juntar à matemática. Nada é mais importante do que a certeza (Wolff, pp. 14-17). Essa ênfase na conjunção entre matemática e filosofia como modelo ideal de conhecimento deixa entrever a influência tanto do espírito cartesiano quanto do sucesso da mecânica de Newton (Arndt, 1983; Blackwell, 1961).

Feita esta distinção entre as formas de conhecimento, Wolff passa então a esclarecer melhor a sua concepção de filosofia. Vimos, anteriormente, que ela tinha sido caracterizada como conhecimento das razões ou causas do que acontece, mas esta é apenas uma determinação parcial e preliminar. A 
definição geral que Wolff nos apresenta é que ela é "a ciência dos possíveis enquanto possíveis" (Wolff, 1728/2006, p. 19) - definição esta que necessita de pelo menos dois esclarecimentos. Em primeiro lugar, por ciência deve-se entender aqui o procedimento lógico-dedutivo, ou seja, o hábito de inferir conclusões legítimas a partir de princípios certos e imutáveis. Nesse sentido, a filosofia deve demonstrar porque alguns possíveis ocorrem (Wolff, pp. 19-20). Em segundo lugar, o conceito wolffiano de possibilidade engloba tanto o que ocorre quanto o que não ocorre. E embora ligue inicialmente a filosofia com a realidade - na medida em que ela deve fornecer as razões (causas) daquilo que existe e acontece -, ele não se restringe à existência concreta (coisas e eventos), mas inclui também o nível metafísico - p.ex., a alma e Deus (entendido aqui como condição última de possibilidade de tudo o que é concretamente possível). Assim, a filosofia seria antes uma ciência do possível que uma ciência do real. De acordo com Schneiders (1983b), Wolff parece aqui querer combinar dois elementos no seu projeto filosófico: ao mesmo tempo em que liberta a filosofia dos grilhões da realidade, obriga-a a explicar como o real é concretizado, isto é, quais são suas razões ou condições (causas).

Para atingir seu objetivo de fornecer as explicações daquilo que é real ou apenas possível, a filosofia deve sempre partir da experiência, pois é através desta última que ela chega aos seus princípios, que por sua vez servirão como premissas para novas conclusões. E como o conhecimento filosófico deve buscar a certeza máxima, a matemática entra aqui em ação, pois ela torna mais perfeita a evidência produzida pela história (Wolff, 1728/2006, pp. 2122). Nas palavras do próprio Wolff, "há coisas na natureza cuja razão só pode ser vista a partir do que é demonstrado matematicamente, uma vez que elas dependem de alguma quantidade ou figura determinada" (p. 22). Uma vez mais é possível perceber como, no projeto wolffiano, a filosofia depende do auxílio do conhecimento tanto histórico como matemático. Como bem notou Engfer, a ciência demonstrativa de Wolff deve ser entendida no contexto tanto da justificativa quanto da descoberta, ou seja, "ela fornece a justificativa teórica para os fatos da experiência, ao mesmo tempo em que permite a dedução de proposições que podem ser confirmadas a posteriori através da experiência" (Engfer, 1983, p. 41).

O último elemento fundamental do projeto de Wolff é a divisão da filosofia em suas disciplinas fundamentais. Seu ponto de partida são os três tipos de ser que podemos descobrir após um exame de nós mesmos: corpos materiais (tudo aquilo que está fora de nossa consciência), almas (aquilo em nós que é consciente de si mesmo) e Deus (autor tanto dos corpos quanto das almas). Num primeiro momento, portanto, a filosofia, buscando as razões para esses três gêneros de ser, deveria conter, respectivamente, três partes: física, psicologia e teologia (Wolff, 1728/2006, pp. 37-39). Como há coisas, porém, que são comuns a todos os seres, deve haver uma parte da filosofia que trate do ser em geral e de suas afecções: a ontologia ou filosofia primeira. E uma vez que ela fornece as noções gerais de todas as outras disciplinas (essência, existência, atributo, modo, necessidade, contingência, etc.), só através dela seria possível desenvolver demonstrativamente o conhecimento filosófico (Wolff, pp. 44-45). Além disso, como são possíveis outros mundos diferente deste, deve haver ainda uma ciência que explique as coisas comuns ao mundo existente e a qualquer outro. Em outras palavras, uma ciência do mundo em geral - a cosmologia geral (Wolff, p. 47). Há, finalmente, a filosofia prática - dividida em ética, política, economia, direito natural -, que trata do uso que o homem faz de sua faculdade apetitiva ao escolher o bem e evitar o mal. Como o que está em jogo é uma faculdade da alma, percebe-se então que a filosofia prática está diretamente relacionada à psicologia (Wolff, pp. 40-43).

Diante dessa divisão da filosofia em várias partes, Wolff vê a necessidade de ordená-las, tomando o método matemático como modelo. Assim, ele elege como princípio ordenador fundamental o de que "as partes que fornecem princípios para as outras devem vir primeiro" (Wolff, 1728/2006, pp. 50-51). No entanto, ele abre uma breve exceção para a lógica - que deveria, de acordo com o método demonstrativo, ser tratada após a ontologia e a psicologia, já que depende dos conhecimentos acerca 
do pensamento humano fornecidos por esta última -, considerando como mais adequado o método de aprendizagem. Nesse caso, a lógica deve preceder todas as outras disciplinas porque sem ela não seria possível familiarizar-se com as demais (Wolff, p. 52). Logo em seguida vem a metafísica (ontologia, cosmologia geral, psicologia e teologia natural), que fornece princípios tanto para a filosofia prática quanto para a física (Wolff, pp. 55-56). Deste modo, teríamos a seguinte ordem: 1) lógica; 2) metafísica; 3) filosofia prática; 4) física. E foi esta ordem que serviu de orientação geral para as publicações latinas de Wolff.

\section{O Papel da Psicologia: A Articulação Entre Experiência e Razão no Estudo da Alma}

Embora o conteúdo essencial da psicologia já tivesse sido explorado em sua famosa "Metafísica Alemã" (Wolff, 1720/1983), foi somente no "Discurso Preliminar" que seu projeto psicológico ganhou seus contornos definitivos. De acordo com a definição e a divisão da filosofia apresentada por Wolff, é possível situar claramente o lugar da psicologia em seu sistema. Em seu sentido mais geral, ela é "aquela parte da filosofia que se ocupa da alma" (Wolff, 1728/2006, p. 39). Assim, ela é parte da metafísica (que tem como objetos de estudo Deus, a alma e o mundo em geral) e está, portanto, a serviço da filosofia como um todo. Isso significa que não há, no pensamento wolffiano, uma autonomia da psicologia, no sentido de uma disciplina separada da atividade filosófica.

Mas Wolff não se contenta com esta definição geral da psicologia. Como todo conhecimento filosófico se caracteriza pela busca de razões para o que é possível, ele acrescenta que a tarefa da psicologia é fornecer então a razão para as coisas que são possíveis através da alma. No entanto, para garantir a certeza deste conhecimento, é preciso começar pela experiência, o único ponto de partida confiável, segundo Wolff. Nesse exato momento, ele vê então a necessidade de uma divisão de tarefas e defende a criação de uma disciplina específica para investigar essa experiência psíquica: a psicologia empírica.
Recorrendo a uma analogia com a física, domínio em que já havia feito uma separação semelhante (física experimental e física dogmática) (Wolff, 1728/2006, pp. 61-63), Wolff define esta nova disciplina como a "ciência que estabelece através da experiência os princípios a partir dos quais pode ser fornecida a razão para o que ocorre na alma humana" (Wolff, p. 64).

Antes de prosseguirmos com a nossa exposição, cabe uma pergunta: se Wolff tinha definido o conhecimento filosófico como distinto do conhecimento meramente empírico (a história), não estaria ele se contradizendo, ao dizer que a psicologia empírica e a física experimental pertencem à filosofia? Esse parece ser um ponto ambíguo no pensamento de Wolff, como alguns autores têm mostrado (e.g., Corr, 1975; École, 1979). O próprio Wolff, contudo, procura esclarecer a questão, postulando a existência de um grau intermediário de conhecimento entre a filosofia propriamente dita e a história:

Está claro, portanto, que a psicologia empírica corresponde à física experimental e pertence, assim, à filosofia experimental [ênfase minha]. Está igualmente claro que a psicologia empírica e a física experimental, quando são exercidas de acordo com o nosso método, não são partes da história. Pois a psicologia empírica não apenas cataloga o que é observado na alma. Ela também estabelece a partir daí conceitos das faculdades e dos hábitos, além de outros princípios. Ela fornece até mesmo a razão para algumas coisas. E aquilo que é próprio do conhecimento filosófico não pode ser classificado como conhecimento meramente histórico. (Wolff, 1728/2006, pp. 64-65)

Logo em seguida, para delimitar o território da psicologia empírica, Wolff vê a necessidade de separá-la do que ele havia anteriormente definido simplesmente como 'psicologia' (ciência que se ocupa com a alma e fornece a razão de tudo o que é possível na alma), criando para esta última o nome de 'psicologia racional'. Segundo ele: 
$\mathrm{Na}$ psicologia racional, derivamos a priori, tendo como base apenas o conceito de alma humana, todas as coisas que são observadas a posteriori como pertencentes à alma e tudo o que é deduzido de certas observações, na medida em que for próprio à filosofia. (Wolff, 1728/2006, p.65)

A principal preocupação de Wolff, ao separar a psicologia empírica da racional, era de caráter prático, a saber, evitar que as pessoas rejeitassem indiscriminadamente o conhecimento psicológico, como se fosse todo ele fruto de especulações fantasiosas. Dada a sua importância para a filosofia prática, Wolff estava muito preocupado em garantir o estabelecimento seguro de princípios psicológicos extraídos da experiência, que pudessem ser posteriormente utilizados como base para a filosofia prática (ética e política, p.ex.) (Wolff, p. 65).

Tendo, então, demarcado conceitualmente o domínio da psicologia e esclarecido a distinção entre a psicologia racional e a psicologia empírica, vamos agora fornecer dois exemplos concretos de como elas operavam. Poucos anos após a publicação do "Discurso Preliminar", Wolff lança separadamente, e com um intervalo de dois anos, seus dois célebres tratados de psicologia, escrevendo, para cada um, uma espécie de resumo geral do assunto em questão (psicologia empírica e psicologia racional). São esses Prolegomena (Wolff, 1980) que servirão aqui de base para nossa exposição.

O modo de proceder da psicologia empírica torna-se claro quando Wolff afirma que a única forma de ter experiência da alma é atentando para as nossas percepções, o que significa que os assuntos tratados pela psicologia empírica só podem ser conhecidos através do exame consciente dos eventos mentais (Wolff, 1980, p. 231). Em outras palavras, Wolff está explicitamente admitindo que a introspecção é o método de investigação psicológica por excelência. Logo em seguida, ele explica melhor como isso deve ser feito:

Sem dúvida, para descobrir conceitos psicológicos, a alma deve ser capaz de extrair de si própria muitas operações. É preciso, portanto, haver experiência de muitas coisas. Pois, a partir dos eventos que trans- correm em nossa alma, nós agrupamos o que pode acontecer e os reduzimos a determinados conceitos. Aquele que deseja ter conceitos correspondentes a termos e estar certo de sua verdade deve tentar experimentar em si mesmo aquelas coisas tratadas na psicologia, ou então reduzir esses termos a outros que ele possa experimentar em si próprio. (Wolff, p. 231)

No que diz respeito à psicologia racional, seu objetivo é fornecer, através de uma cadeia de silogismos, as razões e o correto encadeamento de tudo aquilo que pode ser observado pela psicologia empírica. É preciso, para tanto, um exercício puramente racional de extrair as conseqüências lógicas dos conceitos, exercício esse que extrapola o que a experiência pode oferecer. Por isso, Wolff afirma que o conhecimento adquirido através da psicologia empírica por si só nunca pode nos levar ao conhecimento das razões para o que observamos em nós mesmos (Wolff, 1980, p. 234). E logo adiante, ele esclarece:

Nós podemos atingir este objetivo se nós refletirmos sobre aqueles aspectos da alma observados na psicologia empírica e nos perguntarmos pelo significado dos distintos conceitos lá descobertos, com o objetivo de determinar quais dentre eles podem ser deduzidos a partir de outros. (Wolff, p. 237)

Poderíamos estar induzindo o leitor a uma compreensão equivocada, se, após termos tratado separadamente a psicologia racional e a psicologia empírica, deixássemos de indicar que, na prática, elas trabalham sempre em conjunto. Ou seja, a psicologia é, para Wolff, uma só. Apenas do ponto de vista didático e metodológico justifica-se uma separação. $\mathrm{Na}$ investigação psicológica concreta, porém, as duas permanecem intimamente ligadas e trabalham em uma contínua complementaridade. O melhor exemplo disso é a passagem em que Wolff compara o trabalho psicológico com o astronômico:

O psicólogo imita o astrônomo que deriva teorias de observações e corrobora a teoria através de observações, e que, com a ajuda da teoria, é levado a observações que de outro modo ele poderia não ob- 
ter. Assim, as demonstrações da psicologia racional sugerem o que deveria ser levado em conta na psicologia empírica. E onde quer que esta seja praticada e aquela, cultivada, nós ganhamos muitos princípios que de outra forma só com muita dificuldade poderiam ser estabelecidos. $\mathrm{O}$ melhor, portanto, é unir constantemente o estudo da psicologia racional com o da psicologia empírica, muito embora nós tenhamos considerado prudente tratá-las separadamente. (Wolff, 1980, pp. 232-233)

\section{A Influência Posterior de Wolff Sobre a Psicologia Alemã}

Tendo esclarecido o papel da psicologia no sistema de Wolff, vamos agora, como etapa final de nosso trabalho, indicar, ainda que de forma breve, aqueles que nos parecem ser os principais elementos que ilustram sua influência na história da psicologia.

Em primeiro lugar, é importante ressaltar sua contribuição duradoura para o desenvolvimento da linguagem psicológica. Foi Wolff quem cunhou e/ ou popularizou o vocabulário básico da psicologia alemã, que em grande parte permanecem sendo utilizados. O termo 'representação' (Vorstellung), por exemplo, está presente não só nas discussões psicológicas do século XVIII (e.g., Kant, 1800/2000), mas atravessa todo o século XIX (e.g., Herbart, 1850; Wundt, 1874) e chega firme ao XX, mesmo sofrendo ampliações ou reelaborações (e.g., Freud, 1915/1994). O mesmo acontece com os termos 'consciência' (Bewusstsein) e 'atenção' (Aufmerksamkeit), que são utilizados até hoje para designar processos psíquicos universais (Müsseler, 2008). A lista é grande, mas esses exemplos bastam para que se tenha a dimensão da presença de Wolff na tradição psicológica.

Em segundo lugar, a divisão estabelecida pela primeira vez por Wolff entre a psicologia racional e a psicologia empírica constitui a base de todo o desenvolvimento posterior da tradição psicológica alemã. Vale aqui lembrar que a crítica de Kant à noção de alma como objeto de conhecimento tem como objetivo exatamente a destruição da psicologia racional de Wolff (Kant, 1781/1995). E também que essa crítica de Kant teve uma influência decisiva na constituição de vários projetos de uma psicologia científica ao longo do século XIX, que tinham como idéia norteadora a rejeição da psicologia racional e o aperfeiçoamento da psicologia empírica (e.g., Wundt, 1862). O projeto wundtiano é, de fato, um exemplo privilegiado dos traços deixados na psicologia por Wolff e Kant (Araujo, 2010).

Uma outra influência duradoura de Wolff diz respeito ao método de investigação empírica dos processos mentais: a introspecção. Embora tenha feito algumas considerações sobre a utilidade da observação do comportamento público, foi sobre a auto-observação que Wolff baseou toda a sua psicologia empírica. Ora, a utilização do método introspectivo está presente ao longo de praticamente todo o desenvolvimento posterior da psicologia, especialmente na Alemanha. Logo após Wolff, Tetens também adota o método introspectivo como guia para a investigação psicológica (Tetens, 1777). E mesmo com as duras críticas de Kant (1786/1996) e Comte (1835/1968), alguns dos principais teóricos da chamada 'psicologia científica' tentaram salvar a sua aplicabilidade à pesquisa psicológica, corrigindo-o e reforçando sua confiabilidade (e.g., Wundt, 1888; ver também Titchener, 1912).

Por último, mas não menos importante, gostaríamos de destacar a aposta de Wolff na matematização dos fenômenos mentais. Wolff foi um dos primeiros a utilizar a expressão 'psicometria' (Psycheometria), que aparece pela primeira vez na sua "Psicologia Empírica" de 1732 (Mei, 2011; Witte, 1989). Contudo, já no seu "Discurso Preliminar", em 1728, ele havia postulado a aplicabilidade da matemática a todas as coisas existentes. Como, segundo ele, tudo o que é finito possui certa quantidade e pode, pois, ser medido, os processos mentais, enquanto eventos contingentes, também possuem uma dimensão quantitativa e podem ser objetos de um conhecimento matemático. Como primeiro exemplo, ele alude aos distintos graus de atenção (Wolff, 1728/2006, pp. 8-10). Entretanto, mesmo tendo posteriormente fornecido outros exemplos de fenômenos mentais mensuráveis (p.ex., os graus de prazer e desprazer), é importante ressaltar, como bem notou Feuerhahn (2004), que a psicometria em Wolff aparece apenas como ideal programático, mas 
não como empreendimento realizado. Seja como for, esse programa de Wolff, ainda que através de seus discípulos, teve influência nos debates e nas tentativas de mensuração dos fenômenos psíquicos durante o século XVIII e está relacionado ao surgimento da psicologia experimental no século XIX (Feuerhahn, 2003; Sturm, 2006; Vittadello, 1973).

\section{Conclusão}

Ao longo deste artigo, esperamos ter fornecido evidências suficientes para sustentar nossa tese inicial, a saber, a de que Christian Wolff ocupa um lugar de destaque na história da psicologia, especialmente no que se refere à tradição alemã. Além de ter popularizado a expressão 'psicologia' para designar uma ciência dos fenômenos psíquicos, cunhou alguns dos principais termos do vocabulário psicológico posterior. Além disso, sua 'psicologia empírica' está intimamente relacionada ao desenvolvimento da assim chamada 'psicologia científica' no século XIX. Concluímos, portanto, que Wolff merece mais atenção do que tem até aqui recebido, e isso não só nos manuais de história da psicologia, mas na historiografia da psicologia em geral.

\section{Referências}

Araujo, S. F. (2010). O projeto de uma psicologia científica em Wilhelm Wundt: uma nova interpretação. Juiz de Fora: EDUFJF.

Arndt, H. (1983). Rationalismus und Empirismus in der Erkenntnislehre Christian Wolffs. In W. Schneiders (Hrsg.), Christian Wolff 1679-1754: Interpretationen zu seiner Philosophie und deren Wirkung. Mit einer Bibliographie der Wolff-Literatur [ChristianWolff 1679-1754: Interpretations of his philosophy and its impact. With a bibliography of the literature on Wolff] (pp. 31-47). Hamburg: Meiner.

Beck, L. (1969). Early German philosophy. Cambridge, Mass: Harvard University Press.

Bissinger, A. (1970). Die Struktur der Gotteserkenntnis. Studien zur Philosophie Christian Wolffs [The structure of the knowledge of God. Studies on the philosophy of Christian Wolff]. Bonn: Bouvier.
Blackall, E. (1959). The emergency of German as a literary language. Cambridge: Cambridge University Press.

Blackwell, R. (1961). Christian Wolff's doctrine of soul. Journal of the History of Ideas, 22(3), 339-354.

Boring, E. (1950). A history of experimental psychology (2nd. ed.). New York: Appleton-Century-Crofts.

Bossenbrook, W. (1961). The German mind. Detroit: Wayne State University Press.

Carus, F. (1990). Geschichte der Psychologie [History of Psychology]. Berlin: Springer (Erstausgabe 1808).

Cassirer, E. (1997). A filosofia do iluminismo (3a. ed.). Campinas: Editora da UNICAMP (trabalho originalmente publicado em 1932).

Ciafardone, R. (1983). Von der Kritik an Wolff zum vorkritischen Kant. Wolff-Kritik bei Rüdiger und Crusius. In W. Schneiders (Hrsg.), Christian Wolff 1679-1754: Interpretationen zu seiner Philosophie und deren Wirkung. Mit einer Bibliographie der Wolff-Literatur [ChristianWolff 1679-1754: Interpretations of his philosophy and its impact. With a bibliography of the literature on Wolff] (pp. 289-305). Hamburg: Meiner.

Comte, A. (1968). Cours de philosophie positive : la philosophie chimique et la philosophie biologique [Course of positive philosophy: Chemical philosophy and biological philosophy] (Vol. 3, 5e. ed.). Paris: Anthropos (première édition en 1835).

Copleston, F. (1994). A history of philosophy: From the French enlightenment to Kant (Vol. 6). New York: Image Books (Original work published 1960).

Corr, C. (1975). Christian Wolff's distinction between empirical and rational psychology. Studia Leibnitiana, Supplementa 14, 195-215.

Dessoir, M. (1964). Geschichte der neueren deutschen Psychologie [History of modern German psychology]. Amsterdam: Bonset (Erstausgabe 1901).

École, J. (1979). De la notion de philosophie expérimentale selon Wolff. Les Études Philosophiques, 4, 397-406.

École, J. (1985). Introduction à l'opus metaphysicum de Christian Wolff [Introduction to the metaphysical work of Christian Wolff]. Paris: Vrin.

Engfer, H. -J. (1983). Zur Bedeutung Wolffs für die Methodendiskussion der deutschen Aufklärungsphilosophie. Analytische und synthetische Methode bei Wolff und beim vorkritischen Kant. In W. 
Schneiders (Hrsg.), Christian Wolff 1679-1754: Interpretationen zu seiner Philosophie und deren Wirkung. Mit einer Bibliographie der Wolff-Literatur [Christian Wolff 1679-1754: Interpretations of his philosophy and its impact. With a bibliography of the literature on Wolff] (pp. 48-65). Hamburg: Meiner.

Feuerhahn, W. (2003). Entre métaphysique, mathématique, optique et physiologie: la psychométrie au XVIIIe siècle. Revue Philosophique, 3, 279-292.

Feuerhahn, W. (2004). Die Wolffsche Psychometrie. In O. -P. Rudolph \& J. -F. Goubet (Hgg.), Die Psychologie Christian Wolffs. Systematische und historische Untersuchungen [The psychology of Christian Wolff. Systematic and historical studies] (pp. 227-236). Tübingen: Niemeyer.

Frängsmyr, T. (1975). Christian Wolff's mathematical method and its impact on the eighteenth century. Journal of the History of Ideas, 36, 653-668.

Freud, S. (1994). Das Unbewusste. In S. Freud Studienausgabe [The unconscious. In S. Freud, S. Study Edition] (Band 3, pp. 119-173). Frankfurt a. M: Fischer (Erstausgabe 1915).

Gay, P. (1995). The enlightenment: An interpretation: Vol.

1. The rise of modern paganism. London: Norton (Original work published 1966).

Gerlach, H. -M. (Hrsg.). (2001). Christian Wolff. Seine Schule und seine Gegner [Christian Wolff. His school and his opponents]. Hamburg: Meiner.

González Ruiz, A. (2000). Presentación. En C. Wolff, Pensamientos racionales acerca de Dios, el mundo y el alma del hombre, así como sobre todas las cosas en general (metafísica alemana). Madrid: Akal.

Goodwin, J. (2005). História da psicologia moderna. São Paulo: Cultrix.

Hammerstein, N. (1983). Christian Wolff und die Universitäten. Zur Wirkungsgeschichte des Wolffianismus im 18. Jahrhundert. In W. Schneiders (Hrsg.), Christian Wolff 1679-1754: Interpretationen zu seiner Philosophie und deren Wirkung. Mit einer Bibliographie der Wolff-Literatur [ChristianWolff 1679-1754: Interpretations of his philosophy and its impact. With a bibliography of the literature on Wolff] (pp. 266-277). Hamburg: Meiner.
Hazard, P. (1989). Opensamento europeu no século XVIII ( $3^{a}$. ed.). Lisboa: Presença (trabalho originalmente publicado em 1946).

Hehlmann, W. (1967). Geschichte der Psychologie [History of Psychology] (2. Aufl.) Stuttgart: Kröner.

Herbart, J. (1850). Psychologie als Wissenschaft, neu gegründet auf Erfahrung, Metaphysik und Mathematik [Psychology as a science, newly founded on experience, metaphysics and mathematics] (Band 1, 2. Ausg.) In G. Hartenstein (Hrsg.), Sämmtlichte Werke. Leipzig: Voss.

Hinske, N. (1983). Wolffs Stellung in der deutschen Aufklärung. In W. Schneiders (Hrsg.), Christian Wolff 1679-1754: Interpretationen zu seiner Philosophie und deren Wirkung. Mit einer Bibliographie der Wolff-Literatur [ChristianWolff 1679-1754: Interpretations of his philosophy and its impact. With a bibliography of the literature on Wolff] (pp. 306-319). Hamburg: Meiner.

Kant, I. (1995). Kritik der reinen Vernunft. In W. Weischedel (Hrsg.), Werkeausgabe [Werkausgabe Edition] (Band 4, 13. Aufl.). Frankfurt a.M.: Suhrkamp (Erstausgabe 1781).

Kant, I. (1996). Metaphysische Anfangsgründe der Naturwissenschaft. In W. Weischedel (Hrsg.), Werkeausgabe [Werkausgabe Edition] (Band 9, 13. Aufl.). Frankfurt a.M.: Suhrkamp (Erstausgabe 1786).

Kant, I. (2000). Anthropologie in pragmatischer Hinsicht. In W. Weischedel (Hrsg.), Werkeausgabe [Werkausgabe Edition] (Band 12, 13. Aufl.). Frankfurt a.M.: Suhrkamp (Erstausgabe 1800).

Klemm, O. (1911). Gechichte der Psychologie [History of Psychology]. Leipzig: B. G. Teubner.

Leahey, T. (1980). A history of psychology. Englewood Cliffs, NJ: Prentice-Hall.

Mei, M. (2011). L'intuizione dei pensieri. La pars inferior animae nella psicologia cognitiva di Christian Wolf. Roma: Aracne.

Misiak, H. (1961). The philosophical roots of psychology. New York: Fordham University Press.

Mueller, F.-L. (1978). História da psicologia (2ª̣. ed.). São Paulo: Cia. Editora Nacional.

Murphy, G. (1949). Historical introduction to modern psychology (rev. ed.). New York: Hartcourt, Brace \& World. 
Müsseler, J. (Hrsg.). (2008). Allgemeine Psychologie [General psychology]. (2. Aufl.). Berlin: Springer.

Paulsen, F. (1895). The German universities: Their character and historical development. New York: Macmillan \& Co.

Pongratz, L. (1967). Problemgeschichte der Psychologie [History of the problems of psychology]. Bern: Francke.

Pütz, P. (1978). Die deutsche Aufklärung [The German Enlightenment.]. Darmstadt: Wissenschaftliche Buchgesellschaft.

Richards, G. (1992). Mental machinery. The origins and consequences of psychological ideas, 1600-1850. Baltimore: The John Hopkins University Press.

Röhling, H. (1983). Bemerkungen zur Wirkung Christian Wolffs in Ost- und Südosteuropa. In W. Schneiders (Hrsg.), Christian Wolff 1679-1754: Interpretationen zu seiner Philosophie und deren Wirkung. Mit einer Bibliographie der Wolff-Literatur [ChristianWolff 1679-1754: Interpretations of his philosophy and its impact. With a bibliography of the literature on Wolff] (pp. 278-288). Hamburg: Meiner.

Robinson, D. (1995). An intellectual history of psychology ( $3^{\text {rd }}$. ed.). Madison, Wisconsin: University of Wisconsin Press.

Rudolph, O. -P., \& Goubet, J. -F. (Hgg.). (2004). Die Psychologie Christian Wolffs. Systematische und historische Untersuchungen [The Psychology of Christian Wolff. Systematic and Historical Studies]. Tübingen: Niemeyer.

Schneiders, W. (Hrsg.). (1983a). Christian Wolff 1679. 1754: Interpretationen zu seiner Philosophie und deren Wirkung. Mit einer Bibliographie der Wolff-Literatur [ChristianWolff 1679-1754: Interpretations of his philosophy and its impact. With a bibliography of the literature on Wolff]. Hamburg: Meiner.

Schneiders, W. (1983b). Deus est philosophus absolute summus. Über Christian Wolffs Philosophie und Philosophiebegriff. In W. Schneiders (Hrsg.), Christian Wolff 1679-1754: Interpretationen zu seiner Philosophie und deren Wirkung. Mit einer Bibliographie der Wolff-Literatur [ChristianWolff 1679-1754: Interpretations of his philosophy and its impact. With a bibliography of the literature on Wolff] (pp. 9-30). Hamburg: Meiner.
Schöffler, H. (1956). Deutsches Geistesleben zwischen Reformation und Aufklärung. Von Martin Opitz zu Christian Wolff [German intellectual life between the Reformation and the Enlightenment. Martin Opitz to Christian Wolff]. Frankfurt a.M.: Vittorio Klostermann.

Schultz, D. \& Schultz, S. (2006). História da psicologia

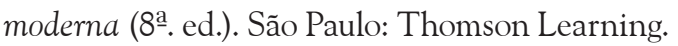
Schwaiger, C. (2000). Christian Wolff. Die zentrale Gestalt der deutschen Aufklärungsphilosophie. In L. Kreimendahl (Hrsg.), Philosophen des 18. Jahrhunderts [Philosophers of the 18th century] (pp. 48-67). Darmstadt: Wissenschaftliche Buchgesellschaft.

Sommer, R. (1966). Geschichte der deutschen Psychologie und Aesthetik [History of German psychology and aesthetics]. Amsterdam: Bonset (Erstausgabe 1892).

Sturm, T. (2006). Is there a problem with mathematical psychology in the eighteenth century? A fresh look at Kant's old argument. Journal of the History of the Behavioral Sciences, 42, 353-377.

Sturm, T. (2009). Kant und die Wissenschaften vom Menschen [Kant and the human sciences]. Paderborn: Mentis.

Tetens, J. N. (1777). Philosophische Versuche über die menschiliche Natur und ihre Entwicklung [Philosophical essays on human nature and its development]. Leipzig: Weidmann.

Titchener, E. B. (1912). The schema of introspection. American Journal of Psychology, 23, 485-508.

Tonelli, G. (1959). Der Streit über die mathematische Methode in der Philosophie in der ersten Hälfte des 18. Jahrhunderts und die Entstehung von Kants Schrift über die "Deutlichkeit". Archiv für Philosophie, 9, 37-66.

Tonelli, G. (1967). Wolff, Christian. In P. Edwards (Ed.), The Encyclopedia of Philosophy (Vol. 8, pp. 340-344). New York: Macmillan Publishing Co. $\&$ The Free Press.

Vidal, F. (2006). Les sciences de l'âme. XVIe-XVIIIe siècle [The sciences of the soul. From the sixteenth to the eighteenth century]. Paris: Honoré Champion.

Viney, W. \& Brett King, D. (2003). A history of psychology. Ideas in context (3rd. ed.). Boston: Allyn and Bacon. 
Vittadello, A. (1973). Expérience et raison dans la psychologie de Christian Wolff. Revue Philosophique de Louvain, 71, 488-511.

Wehner, E. (1990). Geschichte der Psychologie. Eine Einführung [History of psychology. An Introduction]. Darmstadt: Wissenschaftliche Buchgesellschaft.

Witte, W. (1989). Psychometria. In J. Ritter \& J. Gründer (Hgg.), Historisches Wörterbuch der Philosophie [Historical Dictionary of Philosophy] (Band 7, pp. 1678-1681). Basel: Schwabe.

Wolff, C. (1964). Psychologia empirica. In J. École (Hrsg.), Christian Wolff's Gesammelte Werke, II. Abteilung [Christian Wolff's Collected Works, Section II] (Band 5). Hildesheim: Olms (Erstausgabe 1732).

Wolff, C. (1966). Psychologia rationalis. In J. École (Hg.), Christian Wolff's Gesammelte Werke, II. Abteilung. [Christian Wolff's Collected Works, Section II] (Band 6). Hildesheim: Olms (Erstausgabe 1734).

Wolff, C. (1980). Prolegomena to empirical and rational psychology. In R. Richards (Ed.), Christian Wolff's prolegomena to empirical and rational psychology: Translation and commentary. Proceedings of the American Philosophical Society, 124, 227-239.

Wolff, C. (1983) Vernünftige Gedanken von Gott, der Welt und der Seele des Menschen, auch allen din- gen überhaupt. In C. Corr (Hg.), Christian Wolff's Gesammelte Werke, I. Abteilung [Christian Wolff's Collected Works, Section I] (Band 2). Hildesheim: Olms (Erstausgabe 1720).

Wolff, C. (2006). Einleitende Abhandlung über Philosophie im allgemeinen [Introductory essay on philosophy in general] (G. Gawlick und L. Kreimendahl, Übers. und Hgg.). Stuttgart/Bad Cannstatt: FrommannHolzboog (Erstausgabe 1728).

Wolff, H. (1949). Die Weltanschaunng der deutschen Aufklärung [The worldview of the German Enlightenment]. Salzburg: Das Bergland-Buch.

Wundt, M. (1964). Die deutsche Schulphilosophie im Zeitalter der Aufklärung [The German academic philosophy in the Age of Enlightenment]. Hildesheim: Olms (Erstausgabe 1945).

Wundt, W. (1862). Beiträge zur Theorie der Sinneswahrnehmung [Contributions to the theory of sensory perception]. Leipzig und Heidelberg: C. F. Winter.

Wundt, W. (1874). Grundzüge der Physiologischen Psychologie [Fundamentals of Physiological Psychology]. Leipzig: Engelmann.

Wundt, W. (1888). Selbstbeobachtung und innere Wahrnehmung. Philosophische Studien, 4, 292-309. 